\title{
UPF of Cotton Fabrics Printed with Arecanut Slurry
}

\author{
Deepa S. Bhairappanavar* and Jyoti V. Vastrad \\ University of Agricultural Sciences, Dharwad - 580005, Karnataka, India \\ *Corresponding author
}

\section{Keywords}

Cotton, Kokilaksha, mordant, Thickener, Sodium alginate, Blockage percentage

Article Info

Accepted:

18 January 2019

Available Online:

10 February 2019

\section{A B S T R A C T}

The present study was undertaken to investigate the efficiency of natural printed fabric on UV protection. Arecanut slurry was powdered; sodium alginate and kokilaksha seed gums were used for the printing process. Optimization of printing recipe was done using 3 different ratios of dye sources with $0.5 \%$ combination of sodium alginate and kokilaksha seed gums. Screen printed samples were assessed for visual acceptance and colourfastness properties. Samples printed without mordant and with $\mathrm{FeSO}_{4}$ mordant using 0.5\% gum concentration exhibited higher acceptance (WMS) with respect to depth of colour, evenness, sharpness and overall appearance. Based on outcome of the study basic portion and printed portion of cotton fabric were assessed by UPF, UVA, UVB ratings. Samples printed with pure arecanut slurry exhibited highest blockage (UVA: 99.39, UVB: 99.34) compared to other samples. Samples printed with 75:25 arecanut:myrobolan combination exhibited good protection than the 50:50 arecanut:myrobolan printed sample.

\section{Introduction}

The sun-blocking properties of a textile are enhanced when a dye, pigment, delustrant or ultraviolet absorber finish is present that absorbs ultraviolet radiation and blocks its transmission through a fabric to the skin. For this reason, dyed fabrics provide better sun protection than bleached fabrics.

Since naturally-coloured cottons contain pigments that produce shades ranging from light green to $\tan$ and brown, it seemed reasonable to postulate that they would provide better sun protection than conventional bleached cotton, and that natural pigments might prove more durable to laundering and light exposure than dyes, but there is no published research on the ultraviolet transmission values for naturally pigmented cottons (Hustvedt and Crews, 2005).

The purpose of this study was to determine the ultraviolet protection (UPF) values of naturally-printed cotton fabric and the effect of light exposure and laundering on the sunblocking properties of naturally printed cotton.

The global trends in designer collections are more and more focused on clothing influence on human organism. Health hazard caused by UV radiation, recently increasing, forces 
clothing producers to pay attention to giving their products barrier properties that would guarantee the protection against this harmful factor. Fabrics dyed with natural dyeing plants, in a wide range of colours, healthy for human organism and protecting against UV radiation are the requirements of the day (Przewozna and Zimniewska, 2009). Further such fabrics are also popular as Ayurvastra that can fetch utility and functionality in Naturopathy centres and hospitals as bed linen, infant wear, and occupational wear.

Arecanut have been identified as a rich source of flavonols. Seeds of arecanut contain catechin,tannins (15\%), gallic acid, fat, gum and alkaloids like arecoline $(0.07 \%)$, arecaine (1 \%) (Reena et al., 2009). Amount of alkaloid present in Arecanut differs depending on stage of development of the nut. Ecofriendly textile dyeing and printing are new eye openers among health conscious consumers. Natural dyeing is one of the ecofriendly technologies in textile colouration that is gaining more popularity because of the additional benefits of antimicrobial performance (Shenai, 2003).

Hygrophila auriculata (L.) belonging to family Acanthaceae; is also known as Asteracantha longifolia and commonly known as Neermulli, Talmakhana, Kokilakshaand Iksura is a common plant growing in marshy and water logged areas. The plant is an important medicinal herb, widely distributed in India and is used for different medicinal purposes.

With water the seeds develop a large amount of tenacious mucilage (Thankamma, 1999; Nigam et al., 2015). There is no evidence of the use of these seeds in printing.Keeping in vision the above proof the study was taken up with the following objective assessment of ultraviolet protection factor of naturally printed cotton fabrics.

\section{Materials and Methods}

\section{Standardization of printing procedure}

\section{Desizing of cotton}

As the fabric comes from the loom, it has a mixture of impurities and starches within it. Desizing is a common pre-treatment process set to all cellulosic fabrics to eliminate the starch present in the fabric.

The fabric was treated in $5 \mathrm{gpl}$ detergent solution with material-to-liquor ratio (MLR) of 1:40 for 40-45 min to totally wash off the sizing agents and other impurities. The fabric was squeezed and rinsed in running water to make it free from traces of detergent and dried up.

\section{Pre-treatment agent}

In the present study dye powder and myrobolan powder were combined in 50:50 and 75:25 proportions.

\section{Preparation of dye concentrate}

Two per cent arecanut dye powder and myrobolan was soaked according to ratios of 100:0, 50:50 and 75:25 in a separate bowls for 8 hours in $100 \mathrm{ml}$ water. The solutions were boiled for 30 minutes. The extracted dye solutions were made into concentrated forms by boiling it until the volume of the dye liquor reduced to $10 \mathrm{ml}$.

\section{Preparation of mucilage and gum}

For the present experiment, sodium alginate, kokilaksha and 1:1 proportion of sodium alginate and kokilaksha gums were researched using concentrations: $0.1,0.2,0.3,0.4$ and 0.5 per cent respectively. The calculated amount of gum was directly added to the condensed dye solution. 


\section{Mordanting}

Ferrous sulphate mordant was selected for further printing experiments in the present study. 0.4 per cent of ferrous sulphate was mixed in $5 \mathrm{ml}$ water and then added to the printing paste $(10 \mathrm{ml})$.

\section{Preparation of printing paste}

\section{Printing recipe}

Arecanut:myrobolan ratio - 100:0, 50:50, $75: 25$

Gum - Combination of sodium alginate and kokilaksha seed gum

Gum concentration - $0.1 \%, 0.2 \%, 0.3 \%, 0.4$

$\%$, and $0.5 \%$

Mordant - Ferrous sulphate mordant

According to 100:0, 50:50 and 75:25 ratios, arecanut dye powder and myrobolan soaked for 8 hours in $100 \mathrm{ml}$ water. The solutions were boiled for 30 mins for extraction of dye. The extracted dye solution was made into concentrated form by boiling it until the volume of the dye liquor reduced to $10 \mathrm{ml}$.

\section{Printing procedure}

Once the printing paste was ready, screen printing process was carried out on cotton fabrics using screen printing. After printing the fabrics were shade dried.

\section{After treatments for dye fixation}

\section{Steaming and curing}

The printed samples are generally steamed. This process enables the dye molecules to migrate from the surface of the fibres and enter the fabric. Steaming swells the fibres and ensures better penetration of the dye and improves colour fastness properties. After drying the samples were steamed in 20 litre cooker. The samples were rolled in cotton fabric and kept in cooker container and steamed for $30 \mathrm{~min}$ after removal of steam from cooker samples were removed and dried for some time

\section{Visual evaluation of printed samples}

Printed samples were assessed through visual analysis by thirty respondents using questionnaire with five point rating scale for depth of colour, evenness of print, sharpness of print and overall appearance of the print by weighted mean score. Based on the outcome of the survey, 0.5 percent gum concentration was selected for UPF, UVA and UVB testing

\section{Washing}

After steaming the printed samples were given treated with 5 per cent common salt for 30 minutes at room temperature. The fabrics were rinsed thoroughly in running water to remove all the vegetative matter deposited on the print area, rinsed squeezed and dried under shade.

\section{Ultra-violet protection of natural printed cotton fabrics}

UV protection of natural printed fabric was assessed as per the AATCC-183 (2004) test method. It measures the transmittance or blocking of UV radiation through fabrics by UV-VIS spectrophotometer (varian, cary 5000).

The UV profiles of untreated samples were compared with the spectra collected from the same fabrics printed and the effectiveness in shielding UV radiation was evaluated by measuring the UV protection, transmission and reflection. Each measurement is the average of four scans obtained by rotating the 
sample by $90^{\circ}$ the transmission data was used to calculate the UPF, according to the following equation:

$$
\mathrm{UPF}=\frac{\sum_{\lambda=280}^{400} \lambda \times \mathrm{S} \lambda \times \Delta \lambda}{\sum_{\lambda=280}^{400}(\mathrm{E} \lambda \times \mathrm{S} \lambda \times \mathrm{T} \lambda \times \Delta \lambda)}
$$

Where $E \lambda$ is the relative erythermal spectral effectiveness; $S \lambda$, the solar spectral irradiance in $\mathrm{Wm}^{-2} \mathrm{~nm}^{-1}$; $\mathrm{T} \lambda$, the spectral transmission of specimen obtained from UV spectro photometre experiments; and $\Delta \lambda$, the band width in nm (Dubrovski, 2009).

Cotton plain sample and samples printed with different proportions of dye:myrobolan printed samples and ferrous sulphate mordanted samples were subjected to ultraviolet protection factor at SASMIRA Mumbai. The results obtained were rated as per standards and is as below.

\section{Results and Discussion}

\section{UPF ratings and protection category}

Table 1 revealed that UV protection factor of natural printed fabric was assessed as per the AATCC-183 (2004) test method. It measures the transmittance or blocking of UV radiation through fabrics by UV-VIS spectrophotometer (varian, cary 5000). ASTM D6603-00 Standard Guide for Labelling of UV-Protective Textiles provides labelling requirements for textile products intended to protect human beings from UV-A and UV-B (ASTM, 2003).

This document contains terminology for labelling UV-protective textiles. The labelling categories are "good" for UPF fabric values of at least 15 to 24, "very good" for UPF values of 25 to 39 , and "excellent" for UPF values of 40 or higher.
Ultra violet protection of basic portion (plain) of printed cotton fabrics

Table 2 records the UPF rating and the blockage percentage of the (plain portion) natural printed samples. UPF rating of control sample and without myrobolan were 15 each, UVA blockage and UVB blockage percentage of basic portions were 94.89 and 93.82. Sample printed without mordant showed excellent UPF rating (50) that showed excellent protection against UV rays; further UVA and UVB blockage percentage of the pure arecanut printed sample was 99.39 and 99.34 percent.

A chief constituent of the catechu is catechin along with small proportions of brown colouring matter. As the areca catechu contain many flavonoids having great antioxidant property. The property of catechin in human skin is supposed to be the audive ingredient for the treatment of leukodarma. Catechin is a biologically important flovonoids additionally antioxidants from natural sources are found to be a potential for the treatment and prevention of UV rays. The major component from natural sources, especially flavonoids of plants may have a potential for the prevention of UV-mediated diseases such as sunburn and skin cancer (Anurukorakun, 2016).

Table 2: UPF ratings of printed samples with 50:50 proportion of arecanut slurry using sodium alginate andkokilaksha seed gum

Table 3 exhibited that UPF, UVA and UVB ratings of basic and printed portion of 50:50 arecanut:myrobolan printed samples. samples printed with 50:50 arecanut:myrobolan without mordant was 15 and samples printed with 50: 50 arecanut: myrobolan with $\mathrm{FeSO}_{4}$ mordant 14 UPF ratings. Similarly UVA blockage per centage of 50:50 
arecanut:myrobolan without mordant was 95.18 percent and sample printed with 50:50 arecanut: myrobolan with mordant recorded blockage of 95.01 per cent. Feng et al., (2007) reported that fabrics dyes and printed with natural dyes had good ultra violet protection. They could absorb 80-90 per cent of ultraviolet rays. Vidya and Bhanu (2012) reported that dyeing bamboo fabrics with natural colour is increases ultraviolet protection of fabrics and can be considered as an effective protection against ultraviolet rays.

Similarly, UVB blockage of sample printed with 50:50 arecanut:myrobolan proportion with sodium alginate and kokilaksha seed gum without mordant showed 94.11 percent, sample printed with 50:50 arecanut:myrobolan with $\mathrm{FeSO}_{4}$ was 94.24 percent blockage. As a result in the study that is researched the resistance of the cotton fabric against the ultraviolet radiation; it is determined that a prefect protection can be enabled indoors by using UV absorbent, and it is seen that the protection increases depending on the increase of the UV absorbent material (Merdan et. al., 2015).
UPF of printed samples with 75:25 proportion of arecanut slurry and myrobolan using sodium alginate and kokilaksha seed gum

Record presented in Table 4 that UPF, UVA and UVB ratings of sample printed with 75:25 arecanut:myrobolan ratios. Printed portion of the cotton sample exhibited higher UPF rating with 75:25 arecanut:myrobolan proportion without and with mordant each 26 and 24 ratings. Samples printed with 75:25 arecanut:myrobolan with ferrous sulphate mordant recorded UPF rating of 21 and UPF rating for sample oriented with 75:25 arecanut:myrobolan without mordant was 15 that showed good protection from UV rays.

UVA blockage percentage of (plain) 75:25 arecanut:myrobolan samples were 96.55 percent followed by 95.01 percent blockage of ferrous sulphate mordanted samples. Further samples printed with 75:25 arecanut: myrobolan exhibited 97.66 percent blockage and 97.48 percent blockage for 75:25 arecanut:myrobolan combination of sample.

Table.1 UPF ratings and protection category

\begin{tabular}{|l|l|}
\hline UPF range & Protection category \\
\hline $\mathbf{1 5}$ to 24 & Good protection \\
\hline $\mathbf{2 5}$ to 39 & Very good protection \\
\hline $\mathbf{4 0}$ to 50 & Excellent protection \\
\hline
\end{tabular}

Table.2 UPF of printed samples with arecanut slurry using sodium alginate and kokilaksha seed gum

\begin{tabular}{|c|c|c|c|c|}
\hline \multirow{2}{*}{ SI. } & \multicolumn{4}{|c|}{ Basic portion (Plain) } \\
\cline { 2 - 5 } No & Sample & UPF rating & UVA blockage & UVB blockage (\%) \\
& & 15 & 94.89 & 93.82 \\
\hline $\mathbf{1}$ & Basic portion(Plain) & 15 & 95.34 & 94.37 \\
\hline $\mathbf{2}$ & Printed (without myrobolan) & \multicolumn{3}{|c|}{ Printed portion } \\
\hline \multicolumn{5}{|c|}{} \\
\hline $\mathbf{3}$ & Printed (without myrobolan) & 50 & 99.39 & 99.34 \\
\hline
\end{tabular}


Table.3 UPF ratings of printed samples with 50:50 proportion of arecanut slurry using sodium alginate and kokilaksha seed gum

\begin{tabular}{|c|c|c|c|c|}
\hline SI.No & \multicolumn{5}{|c|}{ Basic portion (Plain) } \\
\hline $\mathbf{1}$ & $\begin{array}{c}\text { Sample } \\
\text { Printed with 50:50 } \\
\text { arecanut:myrobolan } \\
\text { (without mordant) }\end{array}$ & UPF rating & UVA blockage (\%) & UVB blockage (\%) \\
\hline $\mathbf{2}$ & $\begin{array}{c}\text { Printed with 50:50 } \\
\text { arecanut:myrobolan } \\
\text { with FeSO }\end{array}$ & 15 & 95.15 & 94.20 \\
\hline & $\begin{array}{c}\text { Printed portion } \\
\text { Sample }\end{array}$ & UPF rating & UVA blockage (\%) & UVB blockage (\%) \\
\hline $\mathbf{3}$ & $\begin{array}{c}\text { Printed with 50:50 } \\
\text { arecanut:myrobolan } \\
\text { (without mordant) }\end{array}$ & 23 & 97.13 & 96.57 \\
\hline $\mathbf{4}$ & $\begin{array}{c}\text { Printed with 50:50 } \\
\text { arecanut:myrobolan } \\
\text { with FeSO }\end{array}$ & 23 & & \\
\hline & & & & \\
\hline
\end{tabular}

Table.4 UPF of printed samples with 75:25 proportions of arecanut slurry and myrobolan using sodium alginate and kokilaksha seed gum

\begin{tabular}{|c|c|c|c|c|}
\hline \multirow{2}{*}{$\begin{array}{l}\text { Sl. } \\
\text { No }\end{array}$} & \multicolumn{4}{|c|}{ Basic portion (Plain) } \\
\hline & Sample & UPF rating & UVA blockage (\%) & UVB blockage (\%) \\
\hline 1 & $\begin{array}{l}\text { Printed with } 75: 25 \\
\text { arecanut:myrobolan } \\
\text { (without mordant) }\end{array}$ & 14 & 95.01 & 94.11 \\
\hline 2 & $\begin{array}{l}\text { Printed portion } 75: 25 \\
\text { arecanut:myrobolan } \\
\text { with } \mathrm{FeSO}_{4}\end{array}$ & 21 & 96.55 & 96.95 \\
\hline \multicolumn{5}{|c|}{ Print portion } \\
\hline & Sample & UPF rating & UVA blockage (\%) & UVB blockage (\%) \\
\hline 3 & $\begin{array}{l}\text { Printed with } 75: 25 \\
\text { arecanut:myrobolan } \\
\text { (without mordant) }\end{array}$ & 26 & 97.66 & 97.3 \\
\hline 4 & $\begin{array}{c}\text { Printed portion } 75: 25 \\
\text { arecanut:myrobolan } \\
\text { with } \mathrm{FeSO}_{4}\end{array}$ & 24 & 97.48 & 97.13 \\
\hline
\end{tabular}

Table 4 showed that UVB blockage percentage of basic portion of the sample with 75:25 arecanut:myrobolan (ferrous sulphate) ratio was 96.95 followed by 94.11 percent blockage in without mordanted sample. Correspondingly, UVB blockage percentage 
of printed sample without myrobolan was 99.34 followed by 96.57 (Printed with 50:50 arecanut:myrobolan with mordant), 97.30 percent for printed with $75.25 \mathrm{~A}: \mathrm{M}$ ratio without mordant and 97.13 percent blockage for samples printed with 75.25 arecanut: myrobolan ratio with $\mathrm{FeSO}_{4}$ mordant correspondingly. This may be due to uniform coating of arecanut dye on the surface of fabric with 1:1 proportion of sodium alginate and kokilaksha seed gum. Areca catechu contains diverse phenolic compounds including condensed tannins that lead to diffusion of the dye molecules on the surface of fabric which inturns gives an additional coating on plain fabric by even deposition of the dye molecules (Pawar et al., 2017).

\section{Conclusion}

Samples were printed with $0.5 \%$ gum concentration with 100:0, 50:50 and 75:25 arecanut:myrobolan dye proportions. Samples printed without myrobolan exhibited highest blockage in without myrobolan oriented sample (UVA: 99.39, UVB: 99.34) compared to other samples. Naturally printed samples with 75:25 arecanut:myrobolan combination exhibited good protection from UV rays.

\section{References}

Anurukvorakun, O., 2016, The involvement of antioxidant and sun protection factors. Int. Acad. Conf. Proc, pp. $149-158$.

Feng, X. X., Zhang, L. L., Chen, J. Y. and Zhang, J. C., 2007, New insights into solar UV-protectives of natural dye. $J$. Cleaner Product., 15: pp. 366-372.

Hustvedt G. and Crews P., 2005, The Ultraviolet Protection Factor of Naturally-pigmented Cotton. The J. of Cotton Sci. 9:47-55.

Merdan N., Canbolat S. and Akin F., 2015, Providing a Protection against Ultraviolet Lights Indoors via Cotton Textiles. Marmara J. Pure App. Sci., Special Issue-1: 83-86.

Nair, U., Bartsch, H. and Nair, J., 2004, Alert for an epidemic of oral cancer due to use of the betal quid substitutes gutkha and pan masala: a review of agents and causative mechanisms, Mutagenesis, 19(5): 251-262.

Pawar, S., Sandeep P. and Adivrelaar, R. V., 2017, Dyeing and polyester nylon with semi synthetic azo dye by chemical modification of natural source arecanut. Natural Prod. Nioprospect., 8(1): 23-29.

Przewozna, K. S. and Zimniewska, M., 2009, Natural dyeing plants as a source of compounds protecting against UV radiation. Herba polonica, 55(3): 311-318.

Reena, R., Authikat, N. and Michael, A., 2009, Study on the arecanut for its antimicrobial properties. Pharmacognosy, 1(1): 42-45.

Shenai, V. A., 2003, Technology of printing. Sevak Publication, Bombay. 1(2): 1050.

Thankamma, A., 1999, Rheumatoid arthritis and Asteracantha longifolia. Ancient Sci. Life, 18(3): 1-3.

\section{How to cite this article:}

Deepa S. Bhairappanavar and jyoti V. Vastrad. 2019. UPF of Cotton Fabrics Printed with Arecanut Slurry. Int.J.Curr.Microbiol.App.Sci. 8(02): 2258-2264.

doi: https://doi.org/10.20546/ijcmas.2019.802.262 